\title{
Automated red cell indices and marrow iron reserves in geriatric patients
}

\author{
C. G. L. RAPER, C. ROSEN, AND M. CHOUDHURY \\ From the Departments of Haematology and Geriatrics, Kingston General Hospital, Hull
}

SUMMARY The marrow iron reserves, automated red cell indices, serum iron, and total iron binding capacity of 69 geriatric patients were recorded. A fall in the mean red cell volume (MCV) to between 71 and $82 \mathrm{fl}$ failed to distinguish between iron deficiency and the 'anaemia of chronic disorders'. However, there was no reserve of marrow iron in the eight patients with an MCV of $70 \mathrm{fl}$ or less.

The widespread use of automation in haematology laboratories has enabled the mean red cell volume (MCV) and the mean corpuscular haemoglobin (MCH) to be accurately determined on all specimens submitted for a haemoglobin estimation. A reduction in red cell volume and haemoglobin content can be detected by automated equipment before it is apparent in the stained blood film (Sharp and Ballard, 1970). A reduction in red cell volume most frequently occurs in iron deficiency, the 'anaemia of chronic disorders', and $\beta$-thalassaemia. In iron deficiency it has been shown that the MCV is reduced before there is any change in the mean corpuscular haemoglobin concentration (MCHC) (Conrad and Crosby, 1962). We have assessed the MCV in relation to the haemoglobin, the stainable marrow iron reserves, the serum iron, the total iron binding capacity, and the percentage saturation of transferrin in a group of geriatric inpatients.

\section{Patients}

Sixty-nine geriatric inpatients were studied soon after admission to an acute geriatric unit. They were investigated for iron deficiency either because they were anaemic or because their home situation suggested inadequate iron intake. None of the patients had been on regular oral iron supplements or received parenteral iron during the previous three months. There were 43 women and 26 men and their ages ranged from 65 to 100 .

In a separate study the haemoglobin and MCV were recorded on 300 consecutive acute geriatric admissions.

Received for publication 20 September 1976

\section{Methods}

Haemoglobin levels and mean red cell volumes were determined on the Coulter ' $S$ '. The MCV potentiometer was adjusted to give a mean MCV of $89 \mathrm{fl}$ and a range of 82-96 $\mathrm{fl}( \pm 2 \mathrm{SD})$ when a group of 250 blood donors for open-heart surgery was studied. Sternal marrow iron reserves were determined by staining a minimum of six marrow particles by the Prussian blue method (Ellis et al., 1964). Iron reserves were assessed by one of us without prior knowledge of the results of the other investigations. The reserves were arbitrarily graded as plentiful, scanty or completely absent. The serum iron, total iron binding capacity, and percentage saturation of transferrin were measured by the Technicon method N62 using fenozine. The method was controlled using the Hyland Automated Chemistry reference serum and Dade Monitrol. Samples were collected in the morning to overcome the known diurnal variation in the serum iron.

\section{Results}

In none of the marrow biopsies was there evidence of either megaloblastic erythropoiesis or a haematological malignancy. In six of the marrows some of the particles had no storage iron yet others had plentiful storage iron. They were classified as having plentiful storage iron but this emphasises that more than one marrow particle should be examined.

Of the 69 patients fully investigated, 63 were anaemic with a haemoglobin below $12.5 \mathrm{~g} / \mathrm{dl}$, and the haemoglobin levels of the whole group ranged between $7.0 \mathrm{~g} / \mathrm{dl}$ and $14.1 \mathrm{~g} / \mathrm{dl}$. Thirty-five patients had an MCV in the normal range and 34 patients 
had an MCV below the normal range. Ten of the men and 25 of the women whose MCV was in the normal range had no storage iron at all, and 16 of the men and 18 of the women whose MCV was below the normal range had storage iron (Fig. 1).

The percentage saturation of transferrin failed to separate the patients with storage iron from those without storage iron both when the MCV was in the normal range and when it was below the normal range (Fig. 2).

Of the 28 patients with a total iron binding capacity above $57 \mu \mathrm{mol} / \mathrm{l}(310 \mu \mathrm{g} / 100 \mathrm{ml})$, only four had storage iron. However, of the 41 patients with a total iron binding capacity below $57 \mu \mathrm{mol} / 1,29$ had storage iron (Fig. 3).

Of the 300 consecutive geriatric admissions, 33 had MCVs below the normal range and, of these, 30 were in the range 71-81fl. The mean MCV of this group was $89 \mathrm{fl}$.

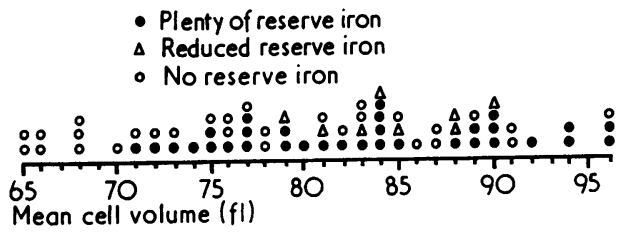

Fig. 1 Marrow iron reserves and mean red cell volume in 69 geriatric patients.

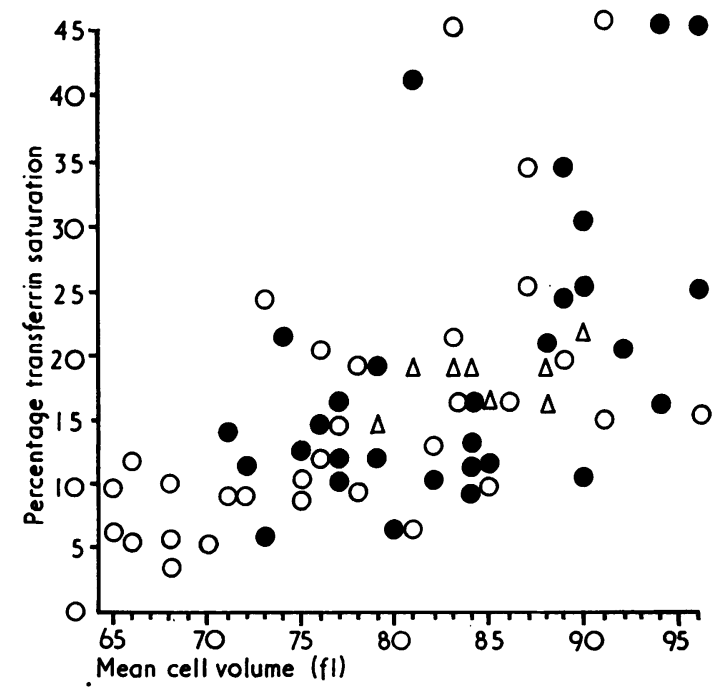

Fig. 2 Relationship between percentage transferrin saturation, mean red cell volume, and marrow iron reserves.

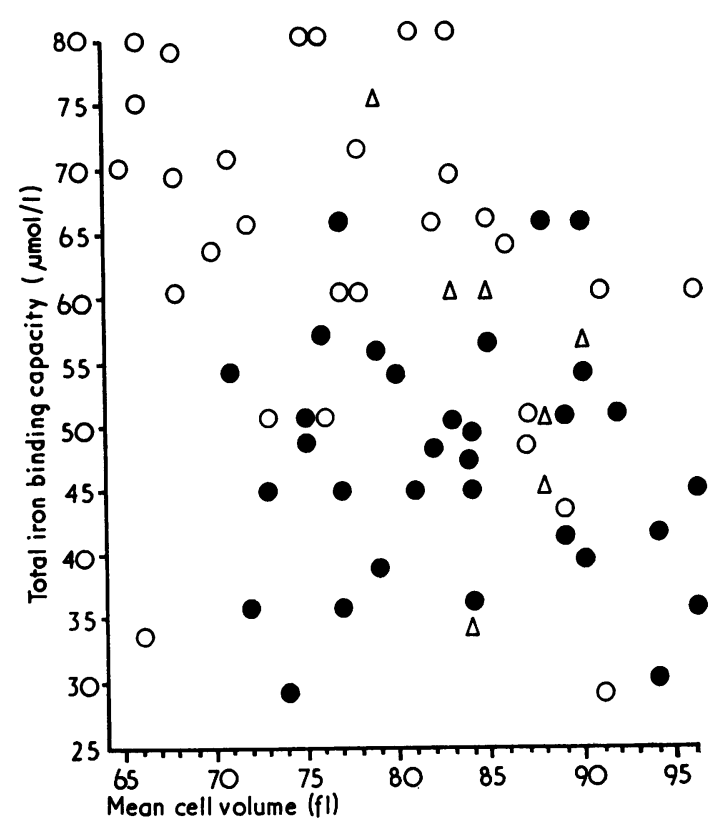

Fig. 3 Relationship between total iron binding capacity, mean red cell volume, and marrow iron reserves.

\section{Discussion}

As the red cell indices are now readily available it is important to know what significance should be attached to the figures, especially since we found that $11 \%$ of all geriatric admissions have an MCV below the range of a healthy population.

The sequence of events in iron deficiency anaemia is that, first, iron is mobilised from the body stores to maintain haemoglobin production and the gastrointestinal absorption of iron is increased. Only when the mobilisation of iron stores and the increased absorption of iron become inadequate does the iron binding capacity of plasma increase and the plasma iron concentration fall. Finally, the supply of iron for haem biosynthesis is inadequate and anaemia occurs, initially with normocytic and normochromic red cells, but later with microcytic and hypochromic cells.

In the 'anaemia of chronic disorders' (Cartwright and Lee, 1971) there is normal or increased marrow storage iron with decreased plasma iron and decreased plasma iron binding capacity, and the red cells are more frequently normocytic and normochromic than microcytic and hypochromic.

It is recognised that both iron deficiency and the anaemia of chronic disorders are common in geriatric patients and the MCV might be expected to help to identify the iron deficient group. However, we found that when the MCV was in the normal 
range many of the patients had no iron reserves. Although most of these patients were anaemic the percentage saturation of transferrin failed to separate those patients with iron stores from those without, and only the elevation of the total iron binding capacity helped to identify the iron deficient group. We agree with the finding in a previous study that only a bone marrow biopsy can prove the absence of iron reserves (Mitchell and Pegrum, 1971).

We found that $9 \%$ of all geriatric inpatient admissions had an MCV in the range 71-82 $\mathrm{fl}$. About half the patients with an MCV in this range who were fully investigated had plentiful iron stores and would not benefit from iron therapy. In this MCV range the anaemia of chronic disorder is as common as iron deficiency, and the percentage transferrin saturation failed to distinguish between the two conditions. The total iron binding capacity was the best indication of iron deficiency in this group, and this confirms previous findings in geriatric patients (Stojceski et al., 1965; Powell and Thomas, 1969). However, there is considerable overlap between the two groups and only bone marrow biopsy can identify the patients without iron reserves. However, there was no reserve of iron in the marrows of the eight patients with an MCV of $70 \mathrm{fl}$ or less, suggesting that only this degree of red cell microcytosis can distinguish between iron deficiency and the anaemia of chronic disorder.
We thank Dr S. R. Datta, Dr P. Horrocks, and Dr J. Knox for allowing us to study patients under their care, and the Biochemistry Department, Hull Royal Infirmary, for carrying out the serum iron estimations.

\section{References}

Cartwright, G. E. and Lee, G. R. (1971). The anaemia of chronic disorders. British Journal of Haematology, 21, 147-152.

Conrad, M. E. and Crosby, W. H. (1962). The natural history of iron deficiency induced by phlebotomy. Blood, 20, 173-185.

Ellis, L. D., Jensen, W. N., and Westerman, M. P. (1964). Marrow iron: an evaluation of depleted stores in a series of 1,332 needle biopsies. Annals of Internal Medicine, 61, 44-49.

Mitchell, T. R. and Pegrum, G. D. (1971). The diagnosis of mild iron deficiency in the elderly. Gerontologia Clinica, 13, 296-306.

Powell, D. E. B. and Thomas, J. H. (1969). The ironbinding capacity of serum in elderly hospital patients. Gerontologia Clinica, 11, 36-47.

Sharp, A. A. and Ballard, B. C. D. (1970). An evaluation of the Coulter S counter. Journal of Clinical Pathology, 23, 327-335.

Stojceski, T. K., Malpas, J. S., and Witts, L. J. (1965). Studies on the serum iron-binding capacity. Journal of Clinical Pathology, 18, 446-452. 